\title{
How Cities can Attract Highly Skilled Workers as Residents: The Impact of City Brand Benefits on Highly Skilled, Potential Residents' City Brand Attitudes: An Abstract
}

\author{
Michael Schade, Rico Piehler, and Christoph Burmann
}

\begin{abstract}
Because highly skilled workers greatly improve the economic development of cities, they compete for this important target group. As a consequence, city brand managers face the challenge to identify factors that influence highly skilled workers' decision for place of residence. Brand attitudes represent a strong predictor of consumer behavior and are mainly determined by brand benefits. Therefore, this paper investigates the effects of city brand benefits (cost efficiency, job chances, social life, recreation, self-brand connection) on highly skilled, potential residents' attitudes toward a city brand. This is the first study that identifies relevant and irrelevant city brand benefits for highly skilled, potential residents using an adequate method (structural equation modeling). Conducting an online survey, 354 evaluations of the 6 largest German cities obtained from 294 highly skilled, potential residents were collected. The results show that social life emerges as the most important city brand benefit. Self-brand connection also positively affects city brand attitudes. In contrast, the benefits cost efficiency, job chances, and recreation do not affect these attitudes. Based on these results, implications for city brand managers and researchers are derived.
\end{abstract}

References Available Upon Request

M. Schade $(\bowtie) \cdot$ R. Piehler $\cdot$ C. Burmann University of Bremen, Bremen, Germany e-mail: mschade@uni-bremen.de; rico.piehler@uni-bremen.de; burmann@uni-bremen.de 